\title{
Extending Doubling to Non-local Domains: Complete vs. Partial Copying + Deletion and Related Reconstruction Issues.
}

\section{Adriana Belletti}

(Appeared in Form, Structure and Grammar. A festschrift Presented to Günther Grewendorf on Occasion of his $60^{\text {th }}$ Birthday, P.Brandt, E.Fuss eds., Akademie Verlag)

Ever since the original work of Cinque (1977), data like the following have been presented to illustrate the island sensitivity of Clitic Left Dislocation (CLLD):
a. ?(?) Gianni, temo
la possibilità che lo
arrestino.
Gianni, I.am.afraid.of the possibility that him(CL) they.will.arrest
b. ?? A Gianni, sono certo del fatto che gli parleranno.
ToGianni, I.am sure of.the fact that to.him(CL) they.will.talk

The relatively better status of (1a) can be related to the interference with the so-called Hanging Topic (HT) construction, discussed in Cinque (1990), which shows no island sensitivity at all. (2) illustrates the HT construction.
a. Quanto a Gianni, temo
la possibilità che lo arrestino.
As for Gianni, I.am.afraid.of the possibility that him(CL) they.will.arrest
b Quanto a Gianni, sono certo del fatto che gli parleranno.
As for Gianni, I.am sure of.the fact that to.him(CL) they.will.talk

The traditional approach to these facts assumes that CLLD involves movement, while HT does not. ${ }^{1}$ Other approaches, like the one recently developed by Frascarelli (2003), assume base generation of CLLD (much as HT) combined with the hypothesis that sensitivity to islands should come from the fact that the dislocated phrase of CLLD undergoes further movement from the left peripheral topic position where it is directly merged into a higher topic position (cf. also Iatridou (1990) for closely related ideas). Following Belletti (2005), I will assume an approach closer to the traditional one that I elaborate along the lines originally developed by Cecchetto (2000). According to this approach, CLLD involves a doubling movement derivation, starting out from an original big DP containing both the clitic and the dislocated phrase. Among the clearest

1 Cinque (1990). In HT, the relation between the Hanging Topic and the clitic is not created through movement but is assumed to be established via some kind of binding relation. Since the Hanging Topic can also be a simple DP and does not need to be introduced by an "as for" phrase, HT and CLLD are hardly distinguishable when the left peripheral phrase is a direct object. 
advantages of this approach is the fact that it does not require any special machinery to ensure the establishment of the correct relations between the dislocated phrase and the clitic with respect to Case, thematic and discourse related interpretation, as discussed in Belletti (2005) in detail. Grewendorf (2002) has also developed a similar approach to Left Dislocation in German; he assumes Left Dislocation to involve movement as well as doubling, where the doubling pronominal element can be a "d-pronoun". ${ }^{2}$

As is expected under the movement analysis, CLLD gives rise to reconstruction effects. Consider the example in (3) from Cecchetto (2000) as a case of a principle C violation induced by reconstruction as well as the examples in (4) illustrating pronoun binding, which appears to be available due to reconstruction:

(3) L'opera prima di [uno scrittore $]_{\mathrm{i}}$, pro $*_{\mathrm{i}}$ la scrive sempre volentieri. The first work of a writer, pro it(CL) writes always with.pleasure (Cecchetto (2000))

(4) a. Isuoi $i_{\mathrm{i}}$ studenti, ogni $\mathrm{i}_{\mathrm{i}}$ professore $\mathrm{li}_{\mathrm{i}}$ promuoverebbe. his students, every professor them would.pass

b. Al suo $\mathrm{i}_{\mathrm{i}}$ studente, ogni $\mathrm{i}_{\mathrm{i}}$ professore sarà autorizzato a parlargli $\mathrm{i}_{\mathrm{i}}$. to his students everyprofessor will.be authorized to talk.to.them

Adopting the doubling approach to CLLD, these facts follow directly: the dislocated phrase originates within the big DP which is located under the scope of the quantifier in (4) and is c-commanded by the preverbal (pro) subject in (3). Assuming a minimalist approach to movement and reconstruction (Chomsky (1993) and subsequent work) in terms of copying and deletion, this means that the dislocated phrase is in fact under the scope of the quantifier in (4) and is c-commanded by the subject in (3): it is just pronounced in the dislocated position and its copy within the original big DP is deleted.

So far we have reviewed and rephrased relatively standard approaches to the analysis of CLLD in current minimalist terms; the core feature of the analysis is the doubling operation that we assume here as well. ${ }^{3}$ Let us now consider some further questions against this background. It is often observed that in non-local domains, resumptive pronouns may "save" island violations. The following Italian data illustrate the point with some examples of restrictive relative clauses where the relativized element is inside a complex NP island. There is a very sharp contrast between the examples in (5), where a gap is present in the clause where the relative head originates, and those in (6), where a resumptive pronoun is present:

$$
\begin{aligned}
& \text { a*L'uomo che temo il pericolo che arresteranno... } \\
& \text { the man whom I.am.afraid.of the danger that they.will.arrest } \\
& \text { b*L'uomo a cui sono certo de fatto che parleranno... } \\
& \text { the man to whom I.am.sure.of the fact that they.will.talk }
\end{aligned}
$$

2 It is maintained here that HT does not involve movement of the topic phrase to the peripheral position. See the discussion below that also addresses the (un)availability of reconstruction.

3 See again Cecchetto (2000), where the reconstruction problem is analyzed in subtler terms uncovering differences in acceptability judgements which he accounts for in terms of reconstruction to the clause internal intermediate topic position. 


\section{a?(?)L'uom che temo il pericolo che lo arresteranno...} the man whom I.am.afraid.of the danger that him(CL)they.will.arrest

$\mathrm{b}$ ?(?) L'uomo che sono certo de fatto che gli
the man whom I.am sure of.the fact that to.him(CL) they.will.talk

The contrast between (5) and (6) is particularly significant in a language like standard Italian which does not systematically form relative clauses with the resumptive pronoun strategy. Relatives like those in (7) are excluded in standard Italian; they are only acceptable at a substandard level (indicated with the diacritic “\%/*“):
a. \%/*L'uomo che lo arresteranno se continua così... the man that him(CL) they.will.arrest if he.goes.on like.that
b. \%/*L'uomo che gli parleranno di sicuro... the man that to.him(CL) they.will.talk for sure

Thus, the status of (6) must be evaluated in comparison to (5) and (7): even if it is substandard since it involves use of a resumptive pronoun within the relative clause, (6) is significantly better than both (5) and (7), respectively, for the following reasons. (7) is marginal since it is substandard; (5) is strongly deviant since it violates an island. Use of the substandard resumptive pronoun strategy brings about an effect of amelioration with respect to the island violation (cf. (6)), while the effect of degradation is quite strong if there is no independent need for the use of the resumptive strategy (cf. (7)). "Saving" the structure from an island violation may be just such an independent need. ${ }^{4}$

It is tempting to analyze the sentences in (6) as involving a doubling derivation, with the head of the relative clause raised to the relevant relative head position and the clitic stranded within the clause. To the extent that CLLD structures have also been assimilated to (clitic) doubling as concerns essential aspects of their computation (cf. again Cecchetto (2000), Belletti (2005)), this amounts to claiming that relative clauses that are formed via the resumptive pronoun strategy are related to CLLD in crucial respects. ${ }^{5}$

Notice now that we seem to come close to an observational dilemma: on the one hand, as noted at the outset, CLLD appears to be sensitive to islands (cf. (1)); on the other hand, adoption of a strategy which parallels CLLD in important respects, such as the use of resumptive pronouns in relatives, leads to the possibility of ameliorating, ultimately saving, the structures from island violations (cf. (6)). How can this be possible? We are faced here with the necessity of providing a better idealization of the relevant data.

The island sensitivity of CLLD of examples like (1) is felt to be relatively strong when compared to the perfect status of HT in (2) (and, more generally, to CLLD in non

4 This is a very general characterization, valid in a language like standard Italian. See Bianchi (2004) for a detailed discussion of different classes of relative clauses correlated with possible/obligatory presence vs. absence of resumptive pronouns in different languages.

5 A raising analysis of relative clauses (Bianchi 1999, Kayne 1994) is particularly appropriate to express this derivation. The only difference between the movement taking place in relatives and the one taking place in CLLD should concern the landing site in the left periphery of the relative head and of the dislocated phrase respectively (Rizzi 1997). In some cases these might coincide, as in appositive relatives. See also Cinque (1981). See also Boeckx (2003) for a general discussion of resumption as involving stranding. 
island contexts), while, as noted, (6) is felt to be relatively acceptable when compared to the clear island violations instantiated in the relative clauses in (5). However, taken in absolute terms, the status of (1) and (6) is essentially comparable: both are marginal as they involve an island violation. We should furthermore add that a substandard flavor is added to (6), due to the presence of the resumptive pronoun in the relative clause.

We are now ready to address the following question: how can (6), despite its marginality and substandard flavor, be nevertheless felt as better than (5), with the plain island violation? This amounts to asking the following: why is there such a sharp difference between the case of a simple gap in the original Merge position of the relative head (cf. (5)) and the case where a resumptive pronoun is present in the same position, modulo cliticization (cf. (6))? Notice that since movement of the head of the relative is involved in both cases, as is implied by the doubling derivation of relatives involving resumption that we assume, the different status cannot be due to occurrence vs. non-occurrence of movement. According to our analysis, the only difference between the two cases is that one involves doubling, while the other does not. The one which does not gives rise to a significantly stronger island violation.

Assuming the copy and deletion approach to movement, the following difference between the two derivations is rather clear: in the resumptive relatives in (6), the original big constituent from which the doubling derivation starts out undergoes deletion of the lexical part which moves to the position of the relative head; the remaining part containing the pronoun does not move out of the clause. Thus, part of the original DP is never extracted out of the island configuration. Intrinsic to the doubling approach is the idea that deletion of the original constituent as a result of movement is necessarily partial, in that the pronoun remains present and is pronounced in the Merge position (modulo cliticization). I would like to propose that this is the crucial factor which helps reduce the locality violation. Since the part of the original big DP containing the pronoun does not move out of the island, an overt part of the big DP never quits the original position within the offending configuration. The pronoun undergoes movement within the island, to perform cliticization in the examples in (6) ${ }^{6}$, but does not move out of it.

When no doubling derivation but movement of the whole constituent takes place, however, the resulting situation is very different. Deletion of the original copy of the relative head is "complete": a full gap is left behind in the base position within the island. In line with the proposal above, this has the consequence that there is no possibility of reducing the locality violation. In sum, I propose that complete vs. partial deletion of the original constituent is at the source of the sharp contrast between (5) and (6).

Since the assumed doubling computation assimilates CLLD and resumptive relatives in important respects ${ }^{7}$, the assumption must be that in CLLD as well, the clause out of which movement of the dislocated constituent occurs always contains part of the

6 The question whether clicization is directly performed by the pronoun or by a silent pro with the clitic directly generated within a clitic head is orthogonal to the discussion here (on cliticization see Sportiche (1998), Belletti (1999) and references cited therein).

7 Modulo the difference in landing site of the left dislocated constituent and the relative head which I have assumed not to play a role in the locality issue addressed here. 
original big constituent, namely the clitic pronoun. However, as already noted, the outcome in CLLD is not felt to be as acceptable as in resumptive relatives. This is to be related to the fact that in this case, the status of the resulting structure does not compare to that of a more deviant structure like that of non-resumptive relatives, but rather to that of a completely well-formed one like that involved in Hanging Topic. Hence the persistent impression of deviance in CLLD out of an island.

Summarizing the discussion so far, I propose that complete vs. partial deletion of the copy of the moved constituent is the crucial factor accounting for the amelioration effect caused by having a resumptive pronoun in relative clauses where the relativized element is inside an island. This strategy is assumed to involve movement of the relative head out of a big DP within the island and a regular doubling computation along the same lines as assumed for CLLD, modulo independent differences between the two processes. ${ }^{8}$

As pointed out in connection with (2), repeated here in (8), no marginality whatsoever is associated with Hanging Topic structures involving an island configuration such as, e.g., a complex noun phrase:
a. Quanto a Gianni, temo
la possibilità che lo
arrestino.
As for Gianni, I.am.afraid.of the possibility that him(CL) they.will.arrest
$\begin{array}{lll}\text { b. Quanto a Gianni, sono certo del fatto che gli } & \text { parleranno. } \\ \text { As for Gianni, I.am sure of.the fact that to.him(CL) they.will.talk }\end{array}$

Hanging Topic thus minimally contrasts with CLLD structures as in (1). Why should this be so? As said above, it could be assumed that the contrast arises from the movement vs. non-movement nature of CLLD and HT, respectively. Although this is certainly a natural hypothesis to make, I would like to tentatively explore a slightly subtler approach now. If we abstract away from island sensitivity, CLLD and HT share a strong resemblance as concerns their syntactic make-up: in both types of structure, a clitic pronoun is present in the clause following the left peripheral phrase which predicates some property of it. It would be most welcome if the account of the two structures could capture this aspect of their resemblance. Within this spirit, let me assume that HT, much as we assumed for CLLD, involves a doubling computation; suppose, however, as is assumed in current accounts (notably, Cinque (1990)), that the peripheral phrase is directly merged in its left peripheral position and that the doubling original big DP contains an empty $\mathrm{DP}^{9}$ and the clitic. The doubling derivation should involve movement of the empty phrase to a left peripheral position within the predicate clause. Furthermore, some discourse principle should ensure that a relation be established between the HT and the empty constituent in the left periphery of the predicate clause to the effect that they are interpreted as referring to the same individual in the discourse context. The line of analysis just sketched preserves the idea that HT is not directly moved from inside the predicate clause, differently from what happens in CLLD, and at the same time interprets the presence of the clitic inside the predicate

$8 \quad$ Such as the more or less standard level of the resulting sentences.

9 I will not go into a deeper discussion of the status of the empty DP at this point (i.e., whether it is an operator or a pronominal element). 
clause in a way identical to the one assumed in CLLD, modulo the non overt nature of the moved portion of the original big DP in the HT case. As for the lack of island sensitivity of HT, an analysis accounting for it could be phrased in the following terms. Suppose that movement of the empty phrase takes place within the island so that no extraction of material from the local domain is performed. The discourse relation between the empty phrase and the HT can be assumed to be established in a way that is not sensible to the same locality constraint(s) as movement operations. The following schemas in (9) illustrate the essence of the proposed derivation for the examples in (2)/(8):
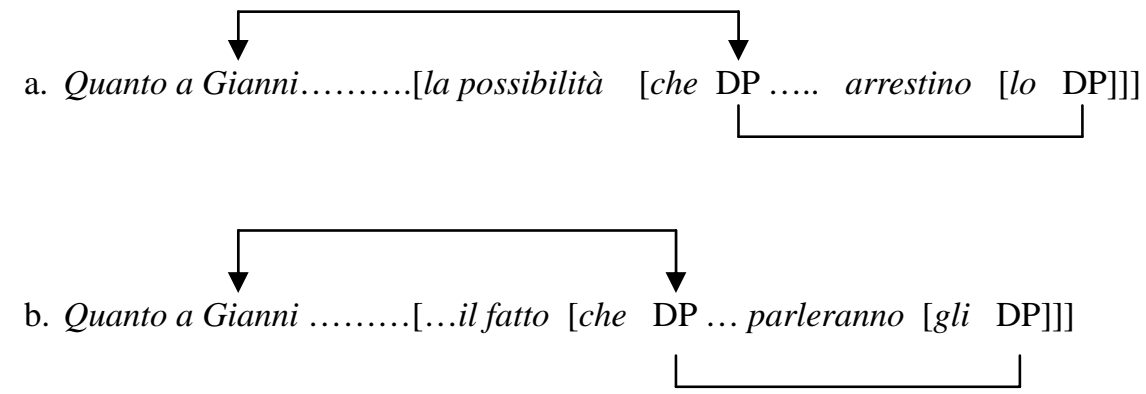

The movement relation is indicated by the line at the bottom of each schema, the interpretive relation between the empty phrase (DP in the schema) and the Hanging Topic is indicated by the upper line terminating with the arrows. As movement takes place inside the island while the relation between the Hanging Topic and the empty phrase occurs outside the island, there is an overall impression of island insensitivity in HT constructions. One major appeal of the outlined approach is that it does not assume special mechanisms to ensure the establishment of the required relation between the HT and the clitic in the predicate clause. The relation is indirectly established through the discourse relation between the HT and the empty DP. On the other hand, the origin of the clitic in the predicate clause is not different from that assumed in CLLD, involving doubling. This is a welcome result in that, as for the presence of the clitic, HT and CLLD should be assimilated to the greatest possible extent. The analysis sketched here assimilates the two structures by having both involve a doubling computation.

Let us make some final, although fairly inconclusive remarks concerning the reconstruction properties of the different structures analyzed here. We already noted in (3)-(4) above the often discussed observation that CLLD gives rise to reconstruction. The proposed analysis of HT gives rise to the expectation that HT as well should admit reconstruction to some extent, at least for those aspects of it relating to the movement nature of the assumed computation. Although clear judgments are hard to get ${ }^{10}$, some

10 Various independent factors are involved which should ultimately account for the extent to which reconstruction is available in different structures. I take the view that movement is just a necessary condition, but not a sufficient one. See Aoun et al. (2001) for relevant discussion. If movement is involved in a given derivation, reconstruction is to be expected; however, other factors, yet to be discovered, may make it available to various extents in different syntactic contexts, up to being totally unavailable. The latter seems to be the case in relative clauses (cf. footnote 12). 
speakers (including myself) do not exclude the bound reading of the clitic pronoun in cases like those in (10), the HT version of the CLLD examples in (4), where reconstruction is clearly possible for all speakers:

(10) a. ?(?)Quanto ai suoi $i_{\mathrm{i}}$ studenti, ogni $i_{\mathrm{i}}$ professore $l_{\mathrm{i}}$ promuoverebbe. As for his students, everyprofessor them would.pass
b. ?(?)Quanto al suo studente, ogni $_{\mathrm{i}}$ professore sarà autorizzato a parlargli . $_{\text {. }}$.
As for his student every professor will.be authorized to talk.to.him

We tentatively suggest that the extent to which reconstruction is felicitously available in HT might depend on the more or less detailed internal analysis that different speakers associate with the moved empty DP, to which the Hanging Topic is related through discourse.

Furthermore, to the extent that CLLD out of an island can be parsed as relatively acceptable ${ }^{11}$, speakers also admit reconstruction of the dislocated phrase inside the island, to an extent varying somewhat among different speakers. Consider (11) in this respect:
(11)?(?)I suoi $i_{\mathrm{i}}$ studenti, temo promuoverebbe.
His students, I.am.afraid.of the possibility that every professor them would.pass

Availability of the bound variable reading in (11) is expected since (11) differs from (4) only as far as the locality of movement of the dislocated phrase is concerned. ${ }^{12}$

11 Although clearly marginal, as any island violation; see the discussion surrounding examples (1), (5) and (6).

12 For reasons which remain to be understood and which are probably orthogonal to the movement/non movement issue, reconstruction to a position inside the island is not readily available for all speakers in resumptive relatives. Sentences like in (i) are hard to parse and excluded by the speakers consulted:
(i) * Quei suoi $i_{\mathrm{i}}$ studenti, che temo la possibilità che ogni $\mathrm{i}_{\mathrm{i}}$ professore $l i_{\mathrm{i}}$ promuoverebbe.
Those of.his students whom I.am.afraid.of the possibility that every professor them would.pass

The interesting issue arises as to how the distinction between CLLD and resumptive relatives should be characterized in this respect, a question which we leave open here. A possibly related issue concerns the fact that all speakers, including those who do not exclude (10), do not admit reconstruction in HT structures which also involve an island violation, cf. (ii):

(ii) * Quanto ai suoi $\mathrm{i}_{\mathrm{i}}$ studenti, temo la possibilità che ogni $\mathrm{i}_{\mathrm{i}}$ professoreli $_{\mathrm{i}}$ promuoverebbe.

As for his students, I.am.afraid.of the possibilitythat every professor themwould.pass

The issue is clearly complex and requires further study. Its complexity suggests that the movement/nonmovement distinction is only one aspect concerned in reconstruction; others are also at play, as hinted at in footnote 10 . 


\section{References}

Aoun, J., L. Choueiri and N.Hornstein, 2001. Resumption, movement and derivational economy. Linguistic Inquiry 32, 371-403.

Belletti, A., 1999. Italian/Romance clitics: Structure and Derivation. In: H. van Riemsdijk (ed.), Clitics in the Languages of Europe, 543-579. Berlin: de Gruyter.

Belletti, A., 2005. Extended doubling and the VP periphery. Probus 17,1, 1-35.

Bianchi, V., 1999. Consequences of Antisymmetry: Headed Relative Clauses. Berlin: de Gruyter.

Bianchi, V., 2004. Resumptive relatives and LF chains. In: L.Rizzi (ed.), The Structure of IP and CP. The Cartography of Syntactic Structures, Volume 2, New York: Oxford University Press.

Boeckx, C., 2003. Islands and Chains : Resumption as Stranding. Amsterdam: John Benjamins.

Cecchetto, C., 2000. Doubling structures and reconstruction. Probus 12, 1, 93-126.

Cinque, G., 1977. The movement nature of left dislocation. Linguistic Inquiry 8, 397411.

Cinque, G., 1981. On the theory of relative clauses and markedness. The Linguistic Review 1, 247-294.

Cinque, G., 1990. Types of A’Dependencies. Cambridge Mass.: MIT Press.

Chomsky, N., 1993. A minimalist program for linguistic theory. In: K. Hale and S.J. Keyser (eds.), The View from Buidling 20, 1-52. Cambridge, Mass.: MIT Press.

Frascarelli, M., 2003. 'Dislocazioni' e ripresa clitica: un'analisi comparata della topicalizzazione in italiano. Ms. University of Rome (talk given at the Interdepartmental Center for Cognitive Studies on Language (ciscl), University of Siena).

Grewendorf, G., 2002. Left dislocation as movement. In: S. Manck and J. Mittelstaedt (eds.), Georgetown University Working Papers in Theoretical Linguistics, 3181.

Iatridou, S., 1990. Clitics and island effects. Penn Working Papers in Linguistics 2, 1130.

Kayne, R., 1994. The Antisymmetry of Syntax. Cambridge, Mass.: MIT Press.

Rizzi, L., 1997. The fine structure of the left periphery. In: L.Haegeman (ed.), Elements of Grammar, 281-337. Dordrecht: Kluwer.

Sportiche, D., 1998. Partitions and Atoms in Clause Structure. London: Routledge. 